\title{
Article
}

\section{High Levels of Antibiotic Resistance Patterns in Two Referral Hospitals during the Post-Ebola Era in Free-Town, Sierra Leone: 2017-2019}

\author{
Zikan Koroma ${ }^{1, *}{ }^{(0}$, Francis Moses $\left.{ }^{1,2}{ }^{(}\right)$, Alexandre Delamou ${ }^{3,4}$, Katrina Hann $\left.^{5}{ }^{(}\right)$, Engy Ali ${ }^{6}$, Freddy Eric Kitutu ${ }^{7}\left({ }^{\circ}\right.$, \\ Juliet Sanyu Namugambe ${ }^{8}$, Doris Harding ${ }^{1}$, Veerle Hermans ${ }^{6}$, Kudakwashe Takarinda ${ }^{9}$, Pruthu Thekkur ${ }^{9}$ (i) \\ and Isatta Wurie ${ }^{2}$
}

check for updates

Citation: Koroma, Z.; Moses, F.; Delamou, A.; Hann, K.; Ali, E.; Kitutu, F.E.; Namugambe, J.S.; Harding, D.; Hermans, V.; Takarinda, K.; et al. High Levels of Antibiotic Resistance Patterns in Two Referral Hospitals during the Post-Ebola Era in Free-Town, Sierra Leone: 2017-2019. Trop. Med. Infect. Dis. 2021, 6, 103. https://doi.org/10.3390/tropicalmed 6020103

Academic Editors: Olga Perovic, Tom Decroo, Chakaya Muhwa Jeremiah and John Frean

Received: 6 April 2021

Accepted: 2 June 2021

Published: 16 June 2021

Publisher's Note: MDPI stays neutral with regard to jurisdictional claims in published maps and institutional affiliations.

Copyright: (c) 2021 by the authors. Licensee MDPI, Basel, Switzerland. This article is an open access article distributed under the terms and conditions of the Creative Commons Attribution (CC BY) license (https:/ / creativecommons.org/licenses/by/ $4.0 /)$.
1 Ministry of Health and Sanitation, Freetown P.O. Box 232, Sierra Leone; franqoline@gmail.com (F.M.); dorisharding@yahoo.com (D.H.)

2 Department of Chemical Pathology, College of Medicine and Allied Health Sciences, University of Sierra Leone, Freetown P.O. Box 232, Sierra Leone; imwurie@aol.com

3 Maferinyah Training and Research Centre, Forécariah 4099, Guinea; adelamou@maferinyah.org or adelamou@cea-pcmt.org

4 Africa Centre of Excellence (CEA-PCMT), University Gamal Abdel Nasser, Conakry 1017, Guinea

5 Sustainable Health Systems, Freetown P.O. Box 232, Sierra Leone; hann.katrina@gmail.com

6 Luxembourg Operational Research Unit (LuxOR), Medical Department, Medecins Sans Frontieres-Operational Centre Brussels, L-1617 Luxembourg, Luxembourg; engy.ali@luxembourg.msf.org (E.A.); Veerle.HERMANS@luxembourg.msf.org (V.H.)

7 Strengthening Pharmaceutical Systems (SPS), Department of Pharmacy, Makerere University School of Health Sciences, Kampala P.O. Box 7072, Uganda; kitutufred@gmail.com

8 Department of Pharmacy, Mbarara University of Science and Technology (MUST), Mbarara P.O. Box 1410, Uganda; julietsanyu@gmail.com

9 Centre for Operational Research, International Union Against Tuberculosis \& Lung Disease (The Union), 75006 Paris, France; ktakarinda@theunion.org (K.T.); pruthu.tk@theunion.org (P.T.)

* Correspondence: zikankoroma@gmail.com; Tel.: +23-27-8222-401

\begin{abstract}
The Post-Ebola era (2017-2019) presented an opportunity for laboratory investments in Sierra Leone. US CDC supported the Ministry of Health and Sanitation to establish a microbiological unit for routine antimicrobial sensitivity testing in two referral (pediatric and maternity) hospitals in Freetown. This study describes resistance patterns among patients' laboratory samples from 2017 to 2019 using routine data. Samples included urine, stool, cerebrospinal fluid, pus-wound, pleural fluid, and high vaginal swabs. Selected Gram-positive and Gram-negative bacterial isolates were tested for antimicrobial susceptibility. Of 200 samples received by the laboratory, 89 returned positive bacterial isolates with urine and pus-wound swabs accounting for $75 \%$ of positive isolates. The number of positive isolates increased annually from one in 2017 to 42 in 2018 and 46 in 2019. Resistance of the cultures to at least one antibiotic was high (91\%), and even higher in the pediatric hospital (94\%). Resistance was highest with penicillin (81\%) for Gram-positive bacteria and lowest with nitrofurantoin $(13 \%)$. Gram-negative bacteria were most resistant to ampicillin, gentamycin, streptomycin, tetracycline, cephalothin and penicillin (100\%) and least resistant to novobiocin ( $0 \%)$. Antibiotic resistance for commonly prescribed antibiotics was high in two referral hospitals, highlighting the urgent need for antimicrobial stewardship and access to reserve antibiotics.
\end{abstract}

Keywords: AMR; laboratory; AMR surveillance; antimicrobial stewardship; operational research; SORT IT; Sierra Leone

\section{Introduction}

The estimated 700,000 deaths occurring globally every year due to antimicrobial resistance (AMR) have elevated its global importance to among the top three health and development threats facing humanity [1]. In the African region, there is a paucity of established AMR surveillance systems as highlighted in a 2014 WHO report [1,2]. Information 
about the status of AMR in West Africa is limited [3,4] although one systematic review in 2017 showed that AMR was common in that region particularly in hospitalized patients with frequent use of first-line antibiotics. And yet, there is weak diagnostic capacity and limited availability of second-line treatment options [5].

For Sierra Leone in particular, there is only limited data on AMR. One study conducted during the 2014-2016 West African Ebola outbreak using laboratory samples (urine and fomite swabs) in an outpatient department in a hospital in Bo district (Sierra Leone), revealed that nearly $86 \%$ of the isolates were multiple drug resistant (MDR) [6]. In addition, this study showed that $64 \%$ of the isolates produced an extended-spectrum B-lactamase (ESBL) resistance pattern [6]. During the same outbreak, most Ebola virus disease (EVD) patients (suspected or confirmed) were routinely given Ciprofloxacin and Cefixime to cover gut bacterial translocation [7]. Concerns were raised regarding the possible over prescription of antibiotics as a routine hospital and community-based treatment and the practice of self- and non-clinician prescriptions on a wider scale even after the outbreak [6].

To date, there is no established AMR surveillance system in Sierra Leone, although plans are on course to establish one [6]. Therefore, identifying clinical isolates and resistance patterns at the health facility level could inform antimicrobial stewardship interventions and contribute to combating antibiotic resistance [8,9]. To remedy the situation and as part of the Post-Ebola Health System Recovery and Strengthening Plan, between 2017 and 2018, the Centers for Disease Control and Prevention (CDC), Atlanta, supported the Ministry of Health and Sanitation (MoHS) to establish a microbiology unit in the laboratory serving two referral hospitals, the pediatric Ola During Children's Hospital (ODCH) and maternal Princess Christian Maternity Hospital (PCMH) in Freetown. This microbiology unit was equipped to perform full bacteriology analysis-culture and antibiotic sensitivity testing (AST). This pilot intervention enhanced routine microbiology services for clinicians and provided information on appropriate antimicrobial therapy to support AMR surveillance in both hospitals and facilitate tracking of AMR patterns. The intervention also focused on capacity building for antimicrobial sensitivity testing. This development provided an opportunity to assess the extent of bacteriological resistance to antibiotics and contribute to better surveillance in Sierra Leone. The results of this study and lessons learnt are crucial to inform the Ministry of Health and Sanitation for not only patient management but for future hospital-based AMR surveillance and antimicrobial stewardship.

This study assessed the presence of bacterial isolates, antimicrobial susceptibility and factors associated with AMR among routinely collected laboratory samples between 2017 and 2019 in two referral hospitals in Freetown, Sierra Leone.

\section{Materials and Methods}

\subsection{Study Design}

This was a descriptive study that analyzed routine hospital laboratory data.

\subsection{Study Settings (General and Specific)}

The study was conducted in Ola During Children's Hospital (ODCH) and Princess Christian Maternity Hospital (PCMH) in Freetown. Both hospitals are the only tertiary hospitals for referrals for pediatric and maternity patients in the capital city. They are situated in the same compound and share a common laboratory which hosts the microbiology unit. Further, samples from these two facilities were taken to the common laboratory hosting the microbiology units for culture and sensitivity testing.

ODCH and PCMH receive average monthly inpatient admissions of 1000 and 850, respectively. Their common laboratory provides service for hematology, biochemistry and microbiology including GeneXpert for tuberculosis. The average monthly number of samples analyzed by the laboratory was 1870 .

Among other routine tests, the microbiology unit performs antimicrobial susceptibility testing and bacterial identification. Clinical samples cultured included urine, blood, stool, cerebrospinal fluid (CSF), pus from wounds, pleural fluid, and high vaginal swabs (HVS). 
Standard operating procedures for culture techniques are employed for all the clinical samples received.

The antimicrobial susceptibility tests were performed using the Kirby-Bauer disk diffusion technique, where standardized inoculum $(0.5 \mathrm{McF}$ arland) from a pure culture was seeded onto sterile Mueller Hinton Agar [10]. Excess moisture on the agar surface was allowed to be absorbed before application of the antimicrobial disks. Gram-positive and Gram-negative antibiotic disks were selected for their bacterial isolates. The plates were incubated aerobically at $35 \pm 2{ }^{\circ} \mathrm{C}$ for $18-24 \mathrm{~h}$, after which zones of inhibition were measured using calipers and interpretation done using the Clinical and Laboratory Standards Institute (CLSI) 2017 Performance Standards for Antimicrobial Susceptibility Testing [10]. Based on the CLSI guidelines, inhibition zones were reported as Sensitive, Intermediate or Resistant. The disks and their concentrations in micrograms included: penicillin G (PEN: 1), ampicillin (AMP: 10), nalidixic acid (NAL: 30), tetracycline (TET: 30), nitrofurantoin (NIT: 50), gentamicin (GEN: 10), ciprofloxacin (CIP: 5), erythromycin (ERY: 5), cephalothin (CEP: 30), kanamycin (KAN: 30), streptomycin (STR: 10), trimethoprim/sulfamethoxazole (SXT: 1.2), chloramphenicol (CHL:30) and colistin (COL: 25). These selected antibiotics are commonly prescribed to treat bacterial infections in the general population [11,12].

Bacteria were identified using the microscopic technique. The biochemical tests were performed to identify the Gram-negative isolates, including lactose fermentation, urease, indole and triple sugar iron, and the tube catalase and coagulase to identify the different species of Gram-positive isolates.

\subsection{Study Population and Period}

The study population included all bacterial samples from the pediatric and maternity hospitals with positive isolate cultures undergoing AST, from 2017 to 2019.

\subsection{Data Collection Source}

All samples received for AST at the microbiology unit of ODCH-PCMH laboratory were entered manually into a report ledger and a Microsoft Excel database daily. The results were updated following confirmatory testing and completion of AST verification. Variables recorded included age, sex, reasons for investigation, type of sample, pathogens isolated, and antibiotics used for sensitivity testing. A second laboratory lead double-checked the laboratory database, and a final verification was made by the consultant medical laboratory scientist. The national consultant further checked all information to verify the results and hence conduct a random $10 \%$ check on the ledger and request forms for compliance.

\subsection{Data Analysis and Statistics}

The laboratory electronic database (in Microsoft Excel, Microsoft, Redmond, WA, USA) was imported into Stata 16 software (StataCorp, College Station, TX, USA) for analysis. A descriptive analysis was performed to determine frequencies and proportions from categorical variables. Pearson's chi-square test was used to compare proportions of positive isolates for selected variables with a level of significance set at $p<0.05$ and $95 \%$ confidence level.

\section{Results}

\subsection{Demographic and Clinical Characteristics}

Of the 200 requests received from both ODCH and PCMH, 89 samples returned positive bacterial isolates, of which $26(29 \%)$ were from the maternity hospital and $63(71 \%)$ from the pediatric hospital. Thirty-three positive isolates (37\%) were from males whilst 56 $(65 \%)$ were from females. By age, four (5\%) were neonates, $27(30 \%)$ were infants, $30(34 \%)$ were children and $27(30 \%)$ were adults.

From the two referral hospitals, the number of positive bacterial isolates cultured for antibiotic sensitivity testing increased annually from one in 2017, to 42 in 2018 to 46 in 2019. 
Urine and pus-wound swabs accounted for $75 \%$ of all positive isolates. More than half $(59 \%)$ of the cultured bacterial isolates were from skin and urogenital origin (Table 1$)$.

Table 1. Demographic and clinical characteristics of patients with positive bacterial isolates on cultured AST from two referral hospitals (pediatric and maternity) in Freetown, Sierra Leone from 2017 to 2019.

\begin{tabular}{|c|c|c|c|c|c|c|}
\hline \multirow{2}{*}{ Characteristic } & \multicolumn{2}{|c|}{ Pediatric } & \multicolumn{2}{|c|}{ Maternity } & \multicolumn{2}{|c|}{ Total } \\
\hline & $n$ & $(\%) *$ & $n$ & $(\%) *$ & $n$ & $(\%) *$ \\
\hline Total & 63 & $(100.0)$ & 26 & $(100.0)$ & 89 & $(100.0)$ \\
\hline \multicolumn{7}{|l|}{ Age } \\
\hline Neonates (0-30 days) & 4 & $(6.4)$ & 0 & $(0.0)$ & 4 & $(4.5)$ \\
\hline Infants ( 1 month-2 years) & 27 & $(42.9)$ & 0 & $(0.0)$ & 27 & (30.3) \\
\hline Children (2-18 years) & 29 & $(46.0)$ & 1 & $(3.9)$ & 30 & (33.7) \\
\hline Adults (>18 years) & 2 & $(3.2)$ & 25 & $(96.1)$ & 27 & $(30.3)$ \\
\hline \multicolumn{7}{|l|}{ Gender } \\
\hline Male & 32 & $(50.8)$ & 1 & $(3.9)$ & 33 & $(37.1)$ \\
\hline Female & 31 & $(49.2)$ & 25 & $(96.1)$ & 56 & $(62.9)$ \\
\hline \multicolumn{7}{|l|}{ Year } \\
\hline 2017 & 1 & $(1.6)$ & 0 & $(0.0)$ & 1 & $(1.1)$ \\
\hline 2018 & 25 & $(39.7)$ & 17 & $(65.4)$ & 42 & $(47.2)$ \\
\hline 2019 & 37 & (58.7) & 9 & $(34.6)$ & 46 & (51.7) \\
\hline \multicolumn{7}{|l|}{ Specimen types } \\
\hline CSF & 5 & $(7.9)$ & 1 & $(3.9)$ & 6 & $(6.7)$ \\
\hline HVS & 0 & $(0.0)$ & 9 & $(34.6)$ & 9 & $(10.1)$ \\
\hline Pleural Fluid & 6 & $(9.5)$ & 0 & $(0.0)$ & 6 & $(6.7)$ \\
\hline Pus-wound swabs & 25 & (39.7) & 4 & $(15.4)$ & 29 & $(32.6)$ \\
\hline Stool samples & 0 & $(0.0)$ & 1 & $(3.9)$ & 1 & $(1.1)$ \\
\hline Urine samples & 27 & $(42.9)$ & 11 & $(42.3)$ & 38 & $(42.7)$ \\
\hline \multicolumn{7}{|l|}{ Organ system involved } \\
\hline Respiratory & 7 & $(11.1)$ & 0 & $(0.0)$ & 7 & $(7.9)$ \\
\hline Skin & 19 & $(30.2)$ & 3 & (11.5) & 22 & $(24.7)$ \\
\hline Urogenital & 24 & $(38.1)$ & 6 & $(23.1)$ & 30 & (33.7) \\
\hline Others & 7 & (11.1) & 16 & (61.5) & 23 & $(25.8)$ \\
\hline Not recorded & 6 & $(9.5)$ & 1 & $(3.9)$ & 7 & $(7.9)$ \\
\hline \multicolumn{7}{|l|}{ Lab Department } \\
\hline Microbiology & 62 & $(98.4)$ & 26 & $(100.0)$ & 88 & $(98.9)$ \\
\hline Haematology & 1 & $(1.6)$ & 0 & $(0.0)$ & 1 & $(1.1)$ \\
\hline
\end{tabular}

\subsection{Quarterly Trend of Lab Samples That Showed Bacterial Growth}

In 2017, only one positive bacterial isolate was observed. During 2018 and 2019, the numbers of positive bacterial isolates started increasing in the first quarters and peaked in the second quarters of each year before dipping in the third and fourth quarters in both hospitals (Figure 1).

\subsection{Antimicrobial Resistance Patterns}

Antimicrobial resistance to at least one antibiotic was observed among the $81(91 \%)$ cultures with positive bacterial growth. There was a higher proportion of resistance in the pediatric hospital's samples ( $94 \%$ ) compared to those of the maternity hospital (85\%). The proportion of resistance was higher among neonates (100\%), and among males (97\%). Among specimen types, the proportion of resistance ranged from $83 \%$ for pleural fluid to $100 \%$ for CSF and stool. The proportion of resistance among Gram-positive and Gramnegative bacteria was almost identical (approximately 90\%) (Table 2). 


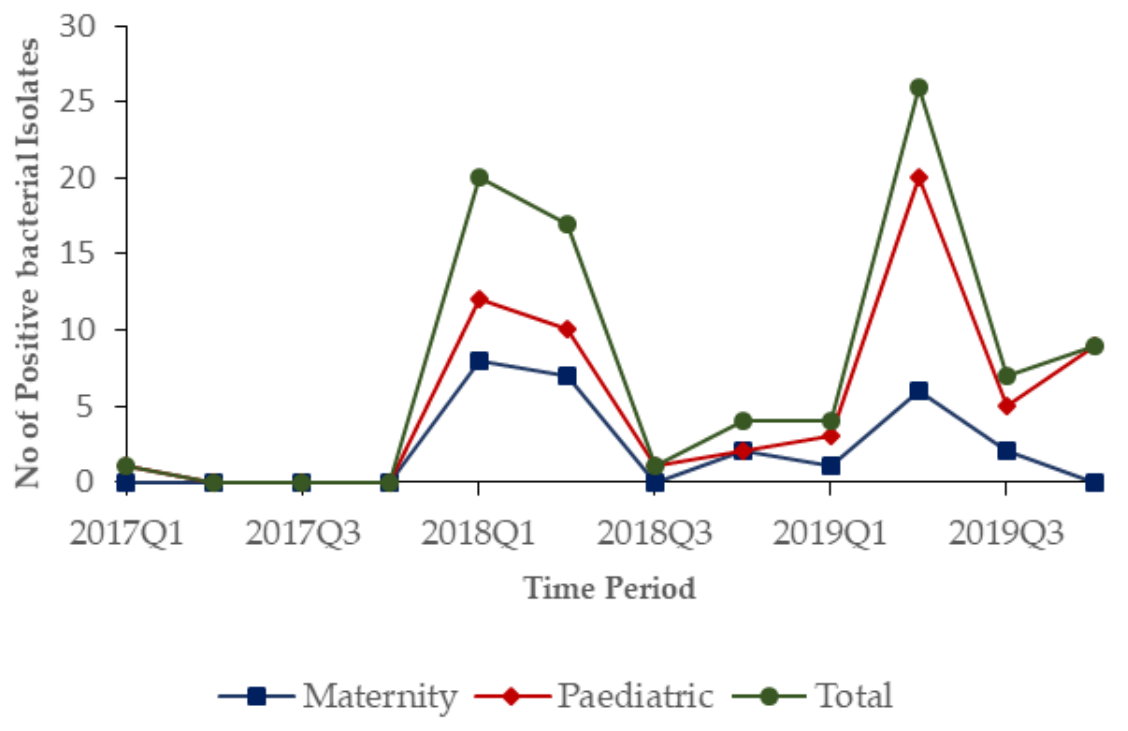

Figure 1. Quarterly trends of lab samples that showed bacterial growth stratified by hospitals in Freetown, Sierra Leone, from 2017-2019.

Table 2. Factors associated with antimicrobial resistance among cultures with bacterial growth from two referral hospitals in Freetown, Sierra Leone from 2017 to 2019.

\begin{tabular}{|c|c|c|c|c|}
\hline \multirow{2}{*}{ Characteristic } & \multirow{2}{*}{ Total } & \multicolumn{2}{|c|}{ Antimicrobial Resistance * } & \multirow{2}{*}{$p$-Value } \\
\hline & & $n$ & $(\%)$ & \\
\hline Total & 89 & 81 & $(91.0)$ & \\
\hline \multicolumn{5}{|l|}{ Hospital type } \\
\hline Paediatric & 63 & 59 & $(93.7)$ & 0.175 \\
\hline Maternity & 26 & 22 & $(84.6)$ & \\
\hline \multicolumn{5}{|l|}{ Time Period } \\
\hline 2017 & 1 & 1 & $(100.0)$ & 0.104 \\
\hline 2018 & 42 & 41 & $(97.6)$ & \\
\hline 2019 & 46 & 39 & $(84.8)$ & \\
\hline \multicolumn{5}{|l|}{ Age } \\
\hline Neonates (0-30 days) & 4 & 4 & $(100.0)$ & 0.755 \\
\hline Infants ( 1 month- 2 years) & 27 & 25 & $(92.6)$ & \\
\hline Children (2-18 years) & 30 & 28 & (93.3) & \\
\hline Adults (>18 years) & 27 & 23 & $(85.2)$ & \\
\hline \multicolumn{5}{|l|}{ Gender } \\
\hline Male & 33 & 32 & $(97.0)$ & 0.131 \\
\hline Female & 56 & 49 & $(87.5)$ & \\
\hline \multicolumn{5}{|l|}{ Specimen types } \\
\hline CSF & 6 & 6 & $(100.0)$ & 0.920 \\
\hline HVS & 9 & 8 & $(88.9)$ & \\
\hline Pleural Fluid & 6 & 5 & (83.3) & \\
\hline Pus-wound swabs & 29 & 27 & $(93.1)$ & \\
\hline Stool samples & 1 & 1 & $(100.0)$ & \\
\hline Urine samples & 38 & 34 & $(89.5)$ & \\
\hline \multicolumn{5}{|l|}{ Organ system involved } \\
\hline Respiratory & 7 & 6 & $(85.7)$ & 0.394 \\
\hline Skin & 22 & 20 & $(90.9)$ & \\
\hline Genital & 30 & 29 & $(96.7)$ & \\
\hline Urinary & 23 & 19 & $(82.6)$ & \\
\hline Others & 7 & 7 & $(100.0)$ & \\
\hline
\end{tabular}


Table 2. Cont.

\begin{tabular}{ccccc}
\hline Characteristic & Total & \multicolumn{2}{c}{ Antimicrobial Resistance * } & \multirow{2}{*}{$\boldsymbol{p}$-Value } \\
\cline { 3 - 3 } & & $\boldsymbol{n}$ & $\mathbf{( \% )}$ & \\
\hline $\begin{array}{c}\text { Lab Department } \\
\text { Microbiology }\end{array}$ & 88 & 80 & $(90.9)$ & 0.752 \\
Haematology & 1 & 1 & $(100.0)$ & \\
\hline Gram staining & & & & \\
Gram Positive & 44 & 40 & $(90.9)$ & 0.973 \\
Gram Negative & 45 & 41 & $(91.1)$ & \\
\hline
\end{tabular}

$\overline{\mathrm{CSF}}=$ Cerebrospinal fluid; HVS = High vaginal swab; ${ }^{*}$ Resistance to at least one antibiotic.

\subsection{Factors Associated with Antimicrobial Resistance}

There were no significant associations between antimicrobial resistance among cultures with bacterial growth and factors investigated: hospital type, time period, patient age and gender, specimen type, organ system, laboratory department or Gram-staining (all $p$-values $>0.05$ ) (Table 2).

\subsection{Antibiotic Sensitivity Testing}

Table 3 presents the antibiotic sensitivity testing and antimicrobial resistance patterns stratified by Gram-staining among samples with positive bacterial isolates. Overall, $52 \%$ of the samples tested were resistant. Antibiotic resistance was significantly higher among Gam-negative bacteria (59\%) than Gram-positive bacteria (46\%), $p=0.0448$. Among Grampositive bacteria, the proportion of antibiotic resistance was highest with penicillin (81\%) and kanamycin $(71.4 \%)$, and lowest with nitrofurantoin (13\%). Among Gram-negative bacteria, antibiotic resistance was highest with six antibiotics: ampicillin, gentamycin, streptomycin, tetracycline, cephalothin and penicillin $(100 \%)$ and lowest with novobiocin $(0 \%)$ (Table 3).

Table 3. Antibiotic sensitivity testing and antimicrobial resistance patterns stratified by Gram-staining among samples with positive bacterial isolates from two referral hospitals (pediatric and maternity) in Freetown, Sierra Leone, from 2017 to 2019.

\begin{tabular}{|c|c|c|c|c|c|c|c|c|c|}
\hline \multirow{3}{*}{ Antibiotic } & \multicolumn{3}{|c|}{ Gram-Positive, $n=246$} & \multicolumn{3}{|c|}{ Gram-Negative, $n=213$} & \multicolumn{3}{|c|}{ Total, $n=459$} \\
\hline & \multirow{2}{*}{$\begin{array}{l}\text { Tested } \\
n\end{array}$} & \multicolumn{2}{|c|}{ Resistant } & \multirow{2}{*}{$\begin{array}{l}\text { Tested } \\
n\end{array}$} & \multicolumn{2}{|c|}{ Resistant } & \multirow{2}{*}{$\begin{array}{l}\text { Tested } \\
n\end{array}$} & \multicolumn{2}{|c|}{ Resistant } \\
\hline & & $n$ & $(\%) \#$ & & $n$ & $(\%) \#$ & & $n$ & $(\%) \#$ \\
\hline Cephalothin & 3 & 2 & $(66.7)$ & 5 & 5 & $(100.0)$ & 8 & 7 & $(87.5)$ \\
\hline Chloramphenicol & 35 & 9 & $(25.7)$ & 34 & 22 & $(64.7)$ & 69 & 31 & $(44.9)$ \\
\hline Gentamycin & 12 & 5 & $(41.7)$ & 1 & 1 & $(100.0)$ & 13 & 6 & $(46.2)$ \\
\hline Ciprofloxacillin & 17 & 6 & $(35.3)$ & 26 & 6 & $(23.1)$ & 43 & 12 & $(27.9)$ \\
\hline Colistrin Sulphate & 5 & 3 & $(60.0)$ & 10 & 4 & $(40.0)$ & 15 & 7 & $(46.7)$ \\
\hline Kanamycin & 7 & 5 & $(71.4)$ & 21 & 15 & $(71.4)$ & 28 & 20 & $(71.4)$ \\
\hline Nalidixic Acid & 7 & 4 & $(57.1)$ & 27 & 14 & $(51.9)$ & 34 & 18 & $(52.9)$ \\
\hline Nitrofurantoin & 8 & 1 & $(12.5)$ & 18 & 8 & $(44.4)$ & 26 & 9 & (34.6) \\
\hline Tetracycline & 21 & 10 & $(47.6)$ & 2 & 2 & $(100.0)$ & 23 & 12 & $(52.2)$ \\
\hline Trimethoprim/Sulfamethoxazole & 29 & 17 & $(58.6)$ & 19 & 17 & $(89.5)$ & 48 & 34 & $(70.8)$ \\
\hline Ampicillin & 4 & 1 & $(25.0)$ & 4 & 4 & $(100.0)$ & 8 & 5 & $(62.5)$ \\
\hline Ceftriaxone & 2 & 1 & $(50.0)$ & 17 & 14 & $(82.4)$ & 19 & 15 & (78.9) \\
\hline Streptomycin & 9 & 4 & $(44.4)$ & 3 & 3 & (100.0) & 12 & 7 & (58.3) \\
\hline Erythromycin & 34 & 19 & (55.9) & 3 & 2 & $(66.7)$ & 37 & 21 & (56.8) \\
\hline Oxacillin & 29 & 10 & (34.5) & 2 & 1 & $(50.0)$ & 31 & 11 & (35.5) \\
\hline Penicillin & 16 & 13 & (81.3) & 1 & 1 & (100.0) & 17 & 14 & (82.4) \\
\hline Imipenem & 2 & 1 & $(50.0)$ & 19 & 6 & $(31.6)$ & 21 & 7 & (33.3) \\
\hline Novobiocin & 6 & 2 & (33.3) & 1 & 0 & $(0.0)$ & 7 & 2 & (28.6) \\
\hline
\end{tabular}

Percentage calculated with the number of Gram-positive, Gram-negative and total as denominator; \# Percentage calculated with the number tested as a denominator. 


\section{Discussion}

This study is one of a limited number of studies reporting on laboratory surveillance of antimicrobial resistance in Sierra Leone in the aftermath of the 2014/2016 EVD outbreak. We found that culture and sensitivity testing during the study period remained low. Most samples with positive bacterial isolates were from the pediatric hospital and among female patients. The finding of this study is similar to studies done in Ethiopia and Nigeria respectively, where there were high positive bacterial isolates found among female patients [13,14]. However, our study found more female positive bacterial isolates from both pediatric and maternity hospitals while in Ethiopia and Nigeria, higher positive bacterial isolate were only reported from pediatric samples.

Antimicrobial resistance was higher in the pediatric hospital, among neonates, males, and in CSF and stool specimens. Similarly, despite using higher sample size, two studies from Nigeria and Egypt found higher positive bacterial isolate among the male neonates [15,16]. There were no statistically significant associations with AMR for factors assessed in this study. Similarly, Youssef et al., in Egypt, found no statistically significant associations with factors assessed in their study exploring the epidemiology of urinary tract infection among neonates in a single intensive care unit [16].

Our findings indicate a low utilization of the laboratory during the study period in terms of culture and sensitivity testing despite a relative increase over time. This might be related to the important gaps in documentation of laboratory requests and samples received for culture and sensitivity testing we found. Further, because the unit was newly established, one reason might be the lack of awareness from health care workers about the availability of the services. Further, as culture and sensitivity testing were provided for free, some Health Care workers might chose to refer their requests to partner external laboratories which grant them percentages of examination costs. In addition, samples selected for testing may have been those from patients who were not showing clinical improvements after empirical antibiotic treatment and hence, were a subset of potential cultures. The laboratory also experienced challenges with a shortage of trained technicians, lack of clinical outcome data, frequent stockouts of supplies and electricity outages, all of which reduced its performance. Another study by Lakoh et al., in Sierra Leone, also highlighted an urgent need for investment in microbiological diagnostics infrastructure and antimicrobial stewardship across the country which contrast with the low use of the available capacities in our study context [17]. This calls for better awareness raising among users but also with hospitals staff to increase the use and documentation of services.

There are important public health implications from our study. First, there is a needs to improve and increase the use of the existing laboratory capacity for culture and drug sensitivity testing not only for better patient management but also as part of surveillance for antimicrobial resistance and improved antibiotic stewardship in the study hospitals and in the country. One approach would be to use the laboratory as referral structure for more health facilities in the area where it is established to increase demand for culture. Second, the laboratory could be integrated in the national AMR surveillance network, which would provide venue for continuous capacity building and provision of supplies. For this to happen, better support from the Ministry of Health and Sanitation in terms of infrastructure, capacity building, human resources, equipment and reagents is needed.

Finally, the low use of available services may be explained by the lack or insufficient trained laboratory technicians, frequent stockouts in supplies or the frequent electricity shortages at the laboratory. Whatever the reasons are, the situation is concerning, especially due to the high levels of AMR found for antibiotics listed by WHO as critically (cephalosporins 3rd to 5th generation and quinolones) and highly (cephalosporins 1st to 2nd generation and penicillin) important human use [18]. Therefore, strong leadership from the study hospitals and the $\mathrm{MoH}$ are needed to improve demand for services and inform AMR surveillance strategies in Sierra Leone. 


\section{Conclusions}

The study highlighted a low uptake of antibiotic sensitivity testing by clinicians in the two referral hospitals in Sierra Leone, and high resistance to commonly prescribed antibiotics in those hospitals. This was in spite of a newly established, dedicated laboratory with this capacity. There is a need for urgent action to improve the use of AST to drive antimicrobial stewardship in these hospitals, and to expand the spectrum of available antibiotics to include 'reserve' antibiotics in clinical care.

Author Contributions: Conceptualization, Z.K., F.M., I.W., A.D., E.A. and K.H.; methodology, Z.K., F.M., A.D., K.H., E.A., K.T. and J.S.N.; formal analysis, Z.K., F.M., K.T. and P.T.; writing-original draft preparation, Z.K., F.M., I.W., A.D., E.A., K.H., V.H., P.T. and J.S.N.; writing-review and editing, I.W., J.S.N., F.E.K., J.S.N., D.H. and E.A. All authors have read and agreed to the published version of the manuscript.

Funding: This SORT IT AMR program was funded by National Institute of Health Research, Department of Health \& Social Care of the United Kingdom and supported by implementing partners.

Institutional Review Board Statement: The study was conducted according to the guidelines of the Declaration of Helsinki. Permission for using the routine program laboratory data was obtained from the Sierra Leone National Ethics Committee (10/12/2019) and the Union Ethics Advisory Group of the Center for Operational Research at the International Union against Tuberculosis and Lung Disease, Paris, France (No.72/19 and 06/11/2019).

Informed Consent Statement: Patient consent was waived due to the use of patient records, for which no human subjects' information was collected.

Data Availability Statement: The data presented in this study are available on request from the corresponding author.

Acknowledgments: This research was conducted through the Structured Operational Research and Training Initiative (SORT IT), a global partnership coordinated by TDR, the Special Program for Research and Training in Tropical Diseases at the World Health Organization (TDR). The specific SORT IT program that led to these publications included a partnership of TDR with WHO Country offices of Ghana, Sierra Leone and Uganda and was implemented along with The Tuberculosis Research and Prevention Center Non-Governmental Organization, Armenia; The International Union Against Tuberculosis and Lung Diseases, Paris and South East Asia offices; Institute of Tropical Medicine, Antwerp, Belgium; Sustainable Health Systems, Freetown, Sierra Leone; Médecins Sans Frontières Luxembourg (LuxOR) Centre National de Formation et de Recherche en Santé Rurale de Maferinyah, Guinea; BahirDar University BahirDar, Ethiopia, Makerere and Lire Universities, Uganda and the University of Salford, United Kingdom. We want to be grateful to the ODCH/PCMH Laboratory Unit, Directorate of Laboratory, Diagnosis and Blood Services and the Ministry of Health and Sanitation for their support in providing the data used for this analysis. We also express our appreciation to the Laboratory Lead in the selected health facilities in Western Area Urban for the support they gave.

Conflicts of Interest: The authors declare no conflict of interest. The funders had no role in the design of the study; in the collection, analyses, or interpretation of data; in the writing of the manuscript, or in the decision to publish the results.

\section{References}

1. O'Neill, J. Tackling Drug-Resistant Infections Globally: Final Report and Recommendations. Government of the United Kingdom 2016. Available online: https:/ / apo.org.au/sites/default/files/resource-files/2016-05/apo-nid63983.pdf (accessed on 4 June 2021).

2. World Health Organization. Antimicrobial Resistance: Global Report on Surveillance; World Health Organization. 2014. Available online: https: / / apps.who.int/iris/handle/10665/112642 (accessed on 4 June 2021).

3. World Health Organization. Antimicrobial Resistance Global Report on Surveillance: 2014 summary; World Health Organization: 2014. Available online: https://apps.who.int/iris/bitstream/handle/10665/112647/WHO_HSE_PED_AIP_2014.2_eng.pdf; jsessionid=920D9EE6A118FD09B25534ADF178F813? sequence $=1$ (accessed on 7 June 2021).

4. Frean, J.; Perovic, O.; Fensham, V.; McCarthy, K.; Von Gottberg, A.; De Gouveia, L.; Poonsamy, B.; Dini, L.; Rossouw, J.; Keddy, K.H.; et al. External quality assessment of national public health laboratories in Africa, 2002-2009. Bull. World Health Organ. 2012, 90, 191-199. [CrossRef] [PubMed] 
5. Bernabé, K.J.; Langendorf, C.; Ford, N.; Ronat, J.-B.; Murphy, R.A. Antimicrobial resistance in West Africa: A systematic review and meta-analysis. Int. J. Antimicrob. Agents 2017, 50, 629-639. [CrossRef] [PubMed]

6. Leski, T.A.; Taitt, C.R.; Bangura, U.; Stockelman, M.G.; Ansumana, R.; Cooper, W.H.; Stenger, D.A.; Vora, G.J. High prevalence of multidrug resistant Enterobacteriaceae isolated from outpatient urine samples but not the hospital environment in Bo, Sierra Leone. BMC Infect. Dis. 2016, 16, 167. [CrossRef] [PubMed]

7. Li, J.; Duan, H.-J.; Chen, H.-Y.; Ji, Y.-J.; Zhang, X.; Rong, Y.-H.; Xu, Z.; Sun, L.-J.; Zhang, J.-Y.; Liu, L.-M.; et al. Age and Ebola viral load correlate with mortality and survival time in 288 Ebola virus disease patients. Int. J. Infect. Dis. 2016, 42, 34-39. [CrossRef] [PubMed]

8. Bebell, L.M.; Muiru, A.N. Antibiotic Use and Emerging Resistance: How Can Resource-Limited Countries Turn the Tide? Glob. Heart 2014, 9, 347-358. [CrossRef] [PubMed]

9. Xavier, B.B.; Lammens, C.; Ruhal, R.; Kumar-Singh, S.; Butaye, P.; Goossens, H.; Malhotra-Kumar, S. Identification of a novel plasmid-mediated colistin-resistance gene, mcr-2, in Escherichia coli, Belgium, June 2016. Eurosurveillance 2016, $21,30280$. [CrossRef] [PubMed]

10. Clinical and Laboratory Standards Institute (CLSI). Performance Standards for Antimicrobial Susceptibility Testing, 27th ed.; CLSI: Wayne, PA, USA, 2017; Volume CLSI Supplement M100.

11. Newman, M.J.; Frimpong, E.; Donkor, E.S.; Opintan, J.A.; Asamoah-Adu, A. Resistance to antimicrobial drugs in Ghana. Infect. Drug Resist. 2011, 4, 215. [PubMed]

12. Opintan, J.; Newman, M.J.; Arhin, R.E.; Donkor, E.S.; Gyansah-Lutterodt, M.; Mills-Pappoe, W. Laboratory-based nationwide surveillance of antimicrobial resistance in Ghana. Infect. Drug Resist. 2015, 8, 379-389. [CrossRef] [PubMed]

13. Duffa, Y.M.; Kitila, K.T.; Gebretsadik, D.M.; Bitew, A. Prevalence and Antimicrobial Susceptibility of Bacterial Uropathogens Isolated from Pediatric Patients at Yekatit 12 Hospital Medical College, Addis Ababa, Ethiopia. Int. J. Microbiol. 2018, 2018, 1-8. [CrossRef] [PubMed]

14. Aiyegoro, O.; Igbinosa, O.; Ogunmwonyi, I.; Odjadjare, E.; Igbinosa, O.; Okoh, A. Incidence of urinary tract infections (UTI) among children and adolescents in Ile-Ife, Nigeria. Afr. J. Microbiol. Res. 2007, 1, 13-19.

15. Meremikwu, M.M.; Nwachukwu, C.E.; Asuquo, A.E.; Okebe, J.U.; Utsalo, S.J. Bacterial isolates from blood cultures of children with suspected septicaemia in Calabar, Nigeria. BMC Infect. Dis. 2005, 5, 110. [CrossRef] [PubMed]

16. Youssef, D.; Elfateh, H.; Sedeek, R.; Seleem, S.; Dm, Y.; Ha, E. Epidemiology of urinary tract infection in neonatal intensive care unit: A single center study in Egypt. J. Acad. Med Sci. 2012, 2, 25. [CrossRef]

17. Lakoh, S.; Li, L.; Sevalie, S.; Guo, X.; Adekanmbi, O.; Yang, G.; Adebayo, O.; Yi, L.; Coker, J.M.; Wang, S.; et al. Antibiotic resistance in patients with clinical features of healthcare-associated infections in an urban tertiary hospital in Sierra Leone: A cross-sectional study. Antimicrob. Resist. Infect. Control. 2020, 9, 1-10. [CrossRef] [PubMed]

18. WHO. Critically Important Antimicrobials for Human Medicine: 5th revision; WHO. 2017. Available online: https:/ /apps.who. int/iris/bitstream/handle/10665/255027/9789241512220-eng.pdf?sequence=1 (accessed on 4 June 2021). 